\title{
ANTIBACTERIAL ACTIVITY OF CHLOROGENIC ACID PHYTOVESICLES AGAINST RESISTANT BACTERIA: DEVELOPMENT, OPTIMIZATION AND EVALUATION
}

\author{
HEMANGI TRIVEDI*, PRASHANT K. PURANIK
}

\author{
Department of Pharmaceutical Sciences, Rashtrasant Tukadoji Maharaj Nagpur University Campus, Nagpur 440033, India
}

Email: hemangirtrivedi@gmail.com

Received: 23 Oct 2021, Revised and Accepted: 18 Nov 2021

\begin{abstract}
Objective: To investigate the in vitro antibacterial activity of a naturally occurring polyphenol chlorogenic acid (CGA) and compares it with formulated chlorogenic acid phytovesicles against 4 different bacterial strains; two gram positive [Staphylococcous aureus and Bacillus subtilis] and two gram negative strains [Klebsiella pneumonia and Escherichia coli]

Methods: CGA phytovesicles were developed and optimized using central composite design to improvise CGA's physicochemical properties. Bactericidal activity was evaluated using agar diffusion, minimum inhibitory concentration (MIC) and time kill assay. The effect of pH and temperature on the antimicrobial activity was determined.

Results: The optimized CGA phytovesicles showed entrapment of $96.89 \%$ with 30 times better lipophilic solubility than the plain drug. The inhibition zone sizes for CGA phytovesicle ranged from 17-25 mm as compared to $15-20 \mathrm{~mm}$ of plain CGA while the MIC values ranged $200-250$ $\mu \mathrm{g} / \mathrm{ml}$ as compared to $500-550 \mu \mathrm{g} / \mathrm{ml}$ of plain CGA. CGA phytovesicles exhibited a strong bactericidal effect at MIC with a log reduction in the range of 0.90-2.04 in Colony forming units (CFUs) at 24h for different strains as compared to 1.38-2.17 of plain CGA. Furthermore, the antibacterial effect was found to augment with increasing temperature but decreased with alkaline $\mathrm{pH}$.
\end{abstract}

Conclusion: Results strongly supports the hypothesis of potential use of CGA phytovesicles as a mode of drug delivery for its antibacterial use against different resistant bacteria.

Keywords: Chlorogenic acid, Phytovesicles, Staphylococcous aureus, Bacillus subtilis, Klebsiella pneumonia, Escherichia coli

(C) 2022 The Authors. Published by Innovare Academic Sciences Pvt Ltd. This is an open access article under the CC BY license (https://creativecommons.org/licenses/by/4.0/) DOI: https://dx.doi.org/10.22159/ijap.2022v14i1.43422. Journal homepage: https://innovareacademics.in/journals/index.php/ijap

\section{INTRODUCTION}

Phytochemicals are the bioactive plant compounds present in functional foods like fruits, vegetables, grains etc. These bioactive compounds not just promote good health but play a major role in prevention of chronic diseases [1]. These bioactive plant compounds which are also known as secondary plant metabolites, possess various benefits including antibacterial properties against pathogenic and spoilage microbes [2]. The increasing antibiotic resistance, limited spectrum and multiple side effects with synthetic agents at an alarming rate, prevails the natural antimicrobials. Unlike the synthetic antibiotics, natural antimicrobials don't target a particular reaction rather act on various groups of biomolecules in a pathogen thus there is no occurrence of resistance which makes them more alluring candidate [3]. However these bioactive compounds or secondary metabolites are limited in their efficacy because of poor absorption with limited solubility in lipophilic phases and instability at different physiological $\mathrm{pH}$ values [4].

The antibacterial efficacy of these secondary metabolites in plants depends on the chemical structure of active components and their concentration. Various phytochemicals present in plants with antibacterial effect includes saponin, flavonoids, thiosulfinates, glucosinolates, phenolics, and organic acids. Among them, Chlorogenic acid (CGA), a polyphenolic derivative of caffeic acid and quinic acid holds as a promising physiologically active substance present in foods such as coffee beans, tea and different fruits like apples, grapes, plums etc [5]. CGA has been reported to have antimicrobial activity against gram negative as well as gram positive bacteria [6]. The antimicrobial activity of polyphenolic derivatives has been imputed by their structure, their $\mathrm{pH}$ and sodium chloride concentration which results in physiological changes in pathogens and consequent cell death [7]. It also possesses other activities such as chemopreventive, antimutagenic, antioxidative, hypoglycemic, antiviral and anti-inflammatory. Its properties are attributed to the phenolic hydroxyl groups and it is characterized by relatively low toxicity and side effects. Till date there have been several literatures on antimicrobial efficiency of CGA against various strains having mechanism of disrupting the cell membranes of microbes [6] and inhibiting the bacterial fatty acid synthesis [8]. It has also been studied against various resistant strains as a synergistic agent along with standard antibiotics $[9,4]$. Despite its safety and effectiveness the use of CGA is limited by its low bioavailability [10]. Low bioavailability is attributed to extensive metabolism, thus despite of having a good hydrophilicity $(40 \mathrm{mg} / \mathrm{ml})$, it has low bioavailability $(17-24 \%)$ and permeability (Biopharmaceutical classification system class III), which in turn affects its biological activities [11]. Moreover, CGA undergoes oxidation during storage or processing [12]. Complexation with phospholipid has not only shown to increase bioavailability by limiting the metabolism and increase in lipophilic solubility, but will also form stable phytovesicular form of CGA because of complexation [13]. Also CGA possesses polar hydroxyl groups in its structure which favours binding with phospholipid to form a phytovesicular complex [14].

Present work is thus aimed to develop and optimize phytovesicular complexes of CGA to improve its bioavailability, permeability and stability which should in turn enhance its antibacterial efficiency against these gram positive and gram negative bacteria. This enhanced activity can act as a source of an antibiotic alternative for drug development against array of infections. Four different bacterial strains Staphylococcous aureus, Bacillus subtilis, Klebsiella pneumonia and Escherichia coli were selected which causes various infections like soft tissue infections, joint infections, Urinary tract infections, nosocomial infections etc. Antibacterial efficiency against them was evaluated using agar diffusion assay, measuring minimum inhibitory concentration (MIC), time kill assay. Further the role of $\mathrm{pH}$ and temperature on antibacterial was also evaluated and compared against plain CGA.

\section{MATERIALS AND METHODS}

\section{Materials}

CGA was purchased from Chemsworth, Surat-394230, India. Dimethyl sulfoxide (DMSO), Dichloromethane, N-hexane were 
obtained from Merck Pvt. Ltd. India. Various bacterial growth mediums like Mueller-Hinton agar (MHA), Mueller-Hinton Broth(MHB) were purchased from Himedia Lab. Pvt. Ltd. Phospholipon $90 \mathrm{H}$ was obtained as a gratis sample from Lipoid, Germany. All the other chemicals were of analytical grade.

\section{Bacterial stains}

Test organisms used were obtained from National collection of industrial microorganisms (NCIM), Pune. Two gram positive strains [Staphylococcous aureus (NCIM 2079) and Bacillus subtilis (NCIM 2063)] and two gram negative strains [Klebsiella pneumonia (NCIM 2036) and Escherichia coli (NCIM 2345)] were selected. The microorganisms were maintained and stored at $4{ }^{\circ} \mathrm{C}$.

\section{Culture conditions}

Organisms obtained were sub cultured in nutrient broth and nutrient agar. A loopful of organisms were transferred from the cultures obtained, in a freshly prepared nutrient broth suspension in an aseptic environment. Similarly a loopful of culture was streaked on an agar slant and incubated at $37^{\circ} \mathrm{C}$ for $24 \mathrm{~h}$. The sub culturing was done every two months.

\section{Standard antibiotic}

Gentamycin (GEN) was used as a standard antibiotic to compare the antibacterial activity of CGA. Gentamycin (Gentalab) of Laborate pharmaceuticals India Ltd. was obtained from a local pharmacy shop.

\section{Formulation of CGA phytovesicles by central composite design}

Central composite design was used to study the influence of different process and formulation variables such as drugphospholipid ratio $\left(\mathrm{X}_{1}\right)$, reaction time $\left(\mathrm{X}_{2}\right)$ and reaction temperature $\left(\mathrm{X}_{3}\right)$ on the quality attributes of phytovesicular complex i.e. partition coefficient and entrapment efficiency (table 1). The effect of these three independent variables at three different levels was evaluated by carrying out trials for 20 different combinations. The data obtained was statically analyzed and validated by Design expert ${ }^{\circledR}$ software (Version 11.0, Stat-Ease Inc., Minneapolis, MN). The design constructed gave the following polynomial Eq. 1.0.

$$
\begin{gathered}
\mathrm{Y}=\mathrm{b} 0+\mathrm{b} 1 \mathrm{X} 1+\mathrm{b} 2 \mathrm{X} 2+\mathrm{b} 3 \mathrm{X} 3+\mathrm{b} 11 \mathrm{X} 12+\mathrm{b} 22 \mathrm{X} 22+\mathrm{b} 33 \mathrm{X} 32+ \\
\mathrm{b} 12 \mathrm{X} 1 \mathrm{X} 2+\mathrm{b} 23 \mathrm{X} 2 \mathrm{X} 3+\mathrm{b} 13 \mathrm{X} 1 \mathrm{X} 3 \text {........Eq. } 1.0
\end{gathered}
$$

Where $\mathrm{Y}$ is the response for all the 20 combinations, $\mathrm{b}_{0}$ is the intercept while $b_{1}$ to $b_{33}$ are coefficients to the variables $X_{1} X_{2} X_{3}$ (main factors). The interaction terms $\left(\mathrm{X}_{1} \mathrm{X}_{2}, \mathrm{X}_{2} \mathrm{X}_{3}\right.$, and $\left.\mathrm{X}_{1} \mathrm{X}_{3}\right)$ showed concurrent changes in response as the factors change. While the linearity was measured by polynomial terms $\left(\mathrm{X}_{12}, \mathrm{x}_{22}, \mathrm{X}_{32}\right)$. Briefly, CGA and Phospholipon $90 \mathrm{H}$ were refluxed with $20 \mathrm{ml}$ of dichloromethane at different molar ratios, reaction times and temperatures. The volume was then reduced to $3-5 \mathrm{ml}$ by continuously stirring and to it $10 \mathrm{ml}$ of $\mathrm{n}$-hexane was added to precipitate the complex. $\mathrm{n}$-hexane was allowed to evaporate at room temperature for 24-48 $\mathrm{h}$. Percentage yield was calculated and the dried complex was further stored in a glass bottle at room temperature [15].

Table 1: Coded levels and actual values for optimization of CGA phytovesicle using central composite design

\begin{tabular}{lllll}
\hline Type of variables & Variables & Levels for optimization & $\mathbf{0}$ & $\mathbf{+ 1}$ \\
\cline { 3 - 5 } & & $\mathbf{- 1}$ & $1: 2$ & $1: 3$ \\
\hline Independent & X1(Drug: Lipid ratio) & $1: 1$ & $2 \mathrm{~h}$ & $3 \mathrm{~h}$ \\
& X2(Reaction time) & $1 \mathrm{~h}$ & $50^{\circ} \mathrm{C}$ & $60^{\circ} \mathrm{C}$ \\
\multirow{2}{*}{ Dependent } & X3(Reaction temperature) & $40{ }^{\circ} \mathrm{C}$ & & \\
& Y1 (Partition Coefficient) & Maximum & & \\
\hline
\end{tabular}

\section{Analytical method of analyzing CGA}

Estimation of CGA content in the complex was carried out by UV spectrophotometer (Jasco (V-630), Japan.) Also Calibration of CGA was performed in methanol, ultrapure water and phosphate buffer saline pH 6.8 (PBS). A standard stock solution of $1000 \mathrm{ppm}$ was prepared, and from this, a $10 \mathrm{ppm}$ solution was prepared to determine the $\lambda \max$ and calibration curves. Various validation parameters like linearity, intraday precision study, interday accuracy study, robustness, ruggedness were determined in accordance with the ICH guidelines [16].

\section{Entrapment efficiency and partition coefficient}

Phytovesicles equivalent to $10 \mathrm{mg}$ of drug were accurately weighed in $100 \mathrm{ml}$ beaker to which $50 \mathrm{ml}$ of $6.8 \mathrm{pH}$ phosphate buffer was added. The beaker was then subjected to stirring on a magnetic stirrer for $4 \mathrm{~h}$ and then allowed to stand for $1 \mathrm{~h}$. Clear supernatant was decanted while the sludge was subjected to centrifugation at $5000 \mathrm{rpm}$ for $15 \mathrm{~min}$. The supernatant obtained after centrifugation was filtered with Whatman filter paper $(0.45 \mu \mathrm{m})$ and was measured for UV absorbance at $328.8 \mathrm{~nm}$. Entrapment efficiency was calculated by following formula Eq. 2.0 [17]

Entrapment efficiency $=\frac{\text { Amount of drug in complex-Amount of free drug obtained }}{\text { Total amount of drug taken }} \times 100$ (........ Eq. 2.0

Solubility of CGA and CGA phytovesicles in both oil and water phase was determined by calculating partition coefficient using shake flask method with water and n-octanol. $10 \mathrm{mg}$ equivalent of phytovesicles were taken in a conical flask to which $10 \mathrm{ml}$ of water and n-octanol was added and then placed upon rotary shaker for $24 \mathrm{~h}$. The mixture was then transferred to a separating funnel and was allowed to stand for $30 \mathrm{~min}$. The amount of drug in both phases was determined by UV spectrophotometer in triplicate. Same procedure was carried out for the plain drug. Concentration in both the phases was calculated using calibration curve equation and partition coefficient was calculated by using equation 3.0. [13]

$$
\text { Partition coefficient }=\mathrm{Co} / \mathrm{Cw} \text {...... Eq. } 3.0
$$

Where Co-concentration in oil phase, $\mathrm{Cw}$-concentration in water phase.

\section{Characterization of phytovesicles}

\section{Fourier transform infra-red (FT-IR) spectroscopy}

The IR spectra of the samples (CGA, Phospholipon 90H, phytovesicles and their physical mixture) were recorded with Fourier transform infrared spectrophotometer (Shimadzu-IRAFFINITY-1, Japan) in the region of $4000 \mathrm{~cm}^{-1}$ to $400 \mathrm{~cm}^{-1}$. Pellets were prepared by triturating sample with potassium bromide using glass pestle and mortar in the ratio 1:100. The mixture was then introduced into the sample holder and scanned. The interaction between CGA and Phospholipon 90H was studied with the spectrums obtained [18].

\section{Differential scanning calorimetery (DSC)}

Thermograms of CGA, Phospholipon $90 \mathrm{H}$, Phytovesicles and their physical mixture were recorded using a differential scanning calorimeter (DSC 60 PLUS, Shimadzu, Japan). The thermal behaviour was studied by heating each individual sample in aluminium seal sample pan under nitrogen gas flow at the heating rate of $5{ }^{\circ} \mathrm{C} / \mathrm{min}$ from 0 to $300^{\circ} \mathrm{C}[19]$.

\section{Particle size analysis and zeta potential}

The particle size, polydispersity index and zeta potential of phytovesicles were determined by a Zetasizer Nano ZS90 (Malvern Instruments Ltd., Massachusetts, USA). For measurement phytovesicles $(10 \mathrm{mg})$ were dispersed in $10 \mathrm{ml}$ deionized water and measured [18]. 


\section{Scanning electron microscopy (SEM)}

SEM imaging of CGA phytovesicles, Phospholipon 90H and CGA was performed by a scanning electron microscope (JEOL, JSM-6390LV, Tokyo, Japan). The sample was mounted on specimen stubs using carbon tape and was coated over with gold using ion sputtering device (JFC 1600). The measurements were performed at $20 \mathrm{kV}$ using different magnifications [19].

\section{Anti-microbial activity}

\section{Agar diffusion assay}

Antibacterial activity of CGA and CGA phytovesicles against Staphylococcous aureus, Bacillus subtilis, Klebsiella pneumonia and Escherichia coli was determined by agar diffusion assay. All the bacterial isolates were grown in nutrient broth and standardized in saline solution to a turbidity of 0.5 McFarland standards. Using sterile cotton swabs the bacterial inoculum $(50 \mu \mathrm{l})$ were then spread onto MHA plates by lawn culture. Wells were created onto the MHA plates using sterilized cork borer $(6 \mathrm{~mm})$. Test solutions $(100 \mu \mathrm{l})$ prepared by dissolving the CGA and CGA phytovesicles in DMSO at a concentration of $2,4,8,16,32 \mathrm{mg} / \mathrm{ml}$ were then carefully loaded into the wells. Gentamycin (GEN) was used as a standard while DMSO was used as negative control. After loading of the sample the plates were kept in refrigerator for $30 \mathrm{~min}$ so that the drug will diffuse before the organisms starts growing. Plates were then further incubated at $37^{\circ} \mathrm{C}$ for $24 \mathrm{~h}$ and observed for growth and inhibition zones around the wells which were then further compared with antibiotic. All measurements were performed in triplicates [20].

\section{Minimum inhibitory concentration (MIC)}

Minimum inhibitory concentration of CGA and CGA phytovesicles for Staphylococcous aureus, Bacillus subtilis, Klebsiella pneumonia and Escherichia coli was determined by broth dilution method. Stock solutions of CGA and CGA phytovesicles were prepared at 1000 $\mu \mathrm{g} / \mathrm{ml}$. 11 sterile test tubes were labelled and arranged. Tubes 2-11 were loaded with $500 \mu \mathrm{l}$ of MHB. While to tubes 1 and 2, $1000 \mu \mathrm{l}$ of CGA stock solution was added. Two fold serial dilution was then performed by pipetting out $500 \mu \mathrm{l}$ of the mixture from test tube 2 to 3 and consecutive transferring mixture till tube $9.500 \mu \mathrm{l}$ of mixture from tube 9 was discarded. Tube 10 and tube 11 served as growth control (with no antibiotic) and broth control respectively. All test tubes were inoculated except the 11th test tube with $500 \mu \mathrm{l}$ of bacterial inoculums ( $0.5 \mathrm{McF}$ arland standard). The tubes were then further incubated at $37^{\circ} \mathrm{C}$ for $24 \mathrm{~h}$. MIC was determined by the lowest concentration showing no visible growth. All measurements were performed in triplicates. The whole procedure was carried out in a laminar air flow in a sterile condition. Also, pippete tips were changed with each transfer so as to avoid the carryover of antibiotic [4].

\section{Time kill assay}

Time Kill assay for CGA and CGA phytovesicles was determined for Staphylococcous aureus, Bacillus subtilis, Klebsiella pneumonia and Escherichia coli to study the effect of time on the bactericidal effect of CGA. Plating technique was employed for which test solutions of CGA and CGA phytovesicles were prepared as per the concentration equal to MIC. Sterile test tubes containing $1000 \mu \mathrm{l}$ of test solution, MHB $(1000 \mu \mathrm{l})$ and $500 \mu \mathrm{l}$ of bacterial inoculum $(0.5 \mathrm{McF}$ arland standards) were incubated on rotary shaker at $37^{\circ} \mathrm{C}$ at $120 \mathrm{rpm}$. A $100 \mu \mathrm{l}$ of aliquot was removed at $0,6,12,18,24 \mathrm{~h}$ and were plated on MHA petri dishes. Two control test tubes were also exercised, one tube containing MHB with no test solution but with bacterial inoculum and one tube containing MHB with no bacterial inoculum but with the test solution. The graph of viable cells (log survival ratio) on the $\mathrm{Y}$ axis and time (in $\mathrm{h}$ ) on $\mathrm{X}$ axis was plotted. All measurements were performed in triplicates [4].

\section{Effect of $\mathrm{pH}$ on antibacterial activity}

A change in the antibacterial activity with changes in $\mathrm{pH}$ was determined. Test solutions of CGA and CGA phytovesicles, at the concentration equivalent to MIC, were prepared in $\mathrm{pH} 4$ sodium acetate buffer, $\mathrm{pH} 7$ and $\mathrm{pH} 10$ phosphate buffer. To the sterile test tube $1000 \mu \mathrm{l}$ of test sample, $1000 \mu \mathrm{l}$ of MHB and $500 \mu \mathrm{l}$ of bacterial inoculum (for all the 4 strains Staphylococcous aureus, Bacillus subtilis, Klebsiella pneumonia and Escherichia coli) was added and further incubated in rotary shaker at $37^{\circ} \mathrm{C}$ for $3 \mathrm{~h} .10$ fold dilutions were made before plating the sample from each test tube onto a MHA plate. After incubation of plates at $37^{\circ} \mathrm{C}$ for $24 \mathrm{~h}$ the CFUs were counted. All measurements were performed in triplicates [20].

\section{Effect of temperature on antibacterial activity}

The role of temperature was determined by using the method described by Kabir et al. [20]. The test solutions of CGA and CGA phytovesicles were exposed to concentration equivalent to MIC, at two different temperatures. After which the test sample was added to $1000 \mu \mathrm{l}$ of MHB and $500 \mu \mathrm{l}$ of bacterial inoculum (for all the 4 strains Staphylococcous aureus, Bacillus subtilis, Klebsiella pneumonia and Escherichia coli) and incubated in a rotary shaker. To determine the CFUs the samples were diluted 10 folds before plating them on MHA plates. The whole experiment was performed in triplicate.

Table 2: Optimization of CGA phytovesicular complex using central composite design

\begin{tabular}{|c|c|c|c|c|c|}
\hline Batch number & $\mathrm{X}_{1}$ drug: lipid ratio & $\mathrm{X}_{2}$ reaction time & $\mathrm{X}_{3}$ reaction temperature & $Y_{1}$ partition coefficient & $Y_{2}$ entrapment efficiency \\
\hline 1 & 1 & 3 & 40 & $0.653 \pm 0.27$ & $73.72 \pm 1.34$ \\
\hline 2 & 2 & 2 & 33.1821 & $0.662 \pm 0.01$ & $74.47 \pm 0.87$ \\
\hline 3 & 3 & 3 & 40 & $0.835 \pm 0.19$ & $66.13 \pm 1.12$ \\
\hline 4 & 3 & 1 & 40 & $0.778 \pm 0.24$ & $68.5 \pm 1.34$ \\
\hline 5 & 2 & 2 & 50 & $0.954 \pm 0.21$ & $69.02 \pm 0.99$ \\
\hline 6 & 2 & 2 & 50 & $0.841 \pm 0.28$ & $75.26 \pm 1.13$ \\
\hline 7 & 3 & 1 & 60 & $0.977 \pm 0.36$ & $96.89 \pm 1.24$ \\
\hline 8 & 1 & 1 & 40 & $0.354 \pm 0.26$ & $84.61 \pm 1.09$ \\
\hline 9 & 2 & 3.68179 & 50 & $0.798 \pm 0.32$ & $83.44 \pm 0.91$ \\
\hline 10 & 0.318207 & 2 & 50 & $0.502 \pm 0.11$ & $71.8 \pm 0.67$ \\
\hline 11 & 2 & 2 & 66.8179 & $0.435 \pm 0.39$ & $75.4 \pm 0.35$ \\
\hline 12 & 2 & 2 & 50 & $1.036 \pm 0.20$ & $81.46 \pm 0.78$ \\
\hline 13 & 3 & 3 & 60 & $0.546 \pm 0.29$ & $81.89 \pm 1.4$ \\
\hline 14 & 1 & 3 & 60 & $0.693 \pm 0.17$ & $64.6 \pm 0.56$ \\
\hline 15 & 2 & 2 & 50 & $0.719 \pm 0.04$ & $78.45 \pm 1.64$ \\
\hline 16 & 2 & 0.318207 & 50 & $0.922 \pm 0.43$ & $72.27 \pm 0.85$ \\
\hline 17 & 2 & 2 & 50 & $0.687 \pm 0.23$ & $80.5 \pm 1.76$ \\
\hline 18 & 2 & 2 & 50 & $0.735 \pm 0.22$ & $77.25 \pm 0.93$ \\
\hline 19 & 3.68179 & 2 & 50 & $0.592 \pm 0.44$ & $82.47 \pm 1.45$ \\
\hline 20 & 1 & 1 & 60 & $0.492 \pm 0.27$ & $69.69 \pm 0.27$ \\
\hline
\end{tabular}

Values were expressed as means $\pm \operatorname{SD}(n=3)$. 


\section{RESULTS AND DISCUSSION}

\section{Optimization of CGA phytovesicles by central composite design}

CGA phytovesicles were optimized by determining the effect of three different variables-drug-phospholipid ratio $\left(\mathrm{X}_{1}\right)$, reaction time $\left(\mathrm{X}_{2}\right)$ and reaction temperature $\left(\mathrm{X}_{3}\right)$ which greatly influenced partition coefficient $\left(\mathrm{Y}_{1}\right)$ and entrapment efficiency $\left(\mathrm{Y}_{2}\right)$ of CGA phytovesicles. A higher value of entrapment efficiency and partition coefficient depicted better complex formation between phospholipid and CGA with increased lipophilic solubility respectively. The results are summed up in table 2. The values measured for entrapment efficiency ranged from 64.6-96.89\% while the values of partition coefficient ranged from 0.354 to 1.036 . Batch (F7) showed highest entrapment of $96.89 \%$ and partition coefficient value of 0.977 as compared to 0.036 of plain CGA and thus it was further selected as the optimized batch. The regression equations in terms of coded factors (Eq. 4 and 5) obtained for-partition coefficient gave correlation coefficient of 0.7338 exhibiting a good fit to quadratic model while for entrapment efficiency it gave correlation coefficient of 0.6703 with good fit of 2 FI model.

$$
\begin{array}{r}
\mathrm{Y} 1=0.8279+0.0802 \mathrm{X} 1-0.0060 \mathrm{X} 2-0.0215 \mathrm{X} 3- \\
0.1092 \mathrm{X} 1 \mathrm{X} 2-0.0335 \mathrm{X} 1 \mathrm{X} 3-0.0733 \mathrm{X} 2 \mathrm{X}-0.0943 \mathrm{X} 12+ \\
0.0163 \mathrm{X} 22-0.0938 \mathrm{X} 32 \ldots \text { Eq. } 4.0
\end{array}
$$

$$
\begin{aligned}
& \left(\mathrm{r}^{2}=0.7595 ; \mathrm{p}=0.0480\right) \\
& \mathrm{Y} 2=76.34+2.76 \mathrm{X} 1-1.01 \mathrm{X} 2+1.52 \mathrm{X} 3-0.0738 \mathrm{X} 1 \mathrm{X} 2+ \\
& \quad 8.40 \mathrm{X} 1 \mathrm{X} 3-0.7538 \mathrm{X} 2 \mathrm{X} 3 \ldots . . \mathrm{Eq} .5 .0
\end{aligned}
$$

\section{$\left(\mathrm{r}^{2}=0.6703 ; \mathrm{p}=0.0120\right)$}

Statistically significant coefficients with $\mathrm{p}$ value of 0.0480 for $\mathrm{Y}_{1}$ and 0.0120 for $Y_{2}$ were obtained for both the responses. Regression analysis showed that drug-phospholipid ratio $\left(\mathrm{X}_{1}\right)$ had a direct relationship and reaction time $\left(\mathrm{X}_{2}\right)$ with reaction temperature $\left(\mathrm{X}_{3}\right)$ had an inverse relationship on partition coefficient $\left(\mathrm{Y}_{1}\right)$. Indicating that partition coefficient values increased with increasing drug phospholipid ratio and decreased with increasing reaction time and temperature. This is because increase in drug phospholipid ratio causes higher quantity of phospholipid to remain in an uncomplexed form forming additional layers encircling CGA phytovesicles rendering good lipophilic character to it [21]. While with increasing reaction time and temperature the phytovesicles formed were sticky and less free flowing owing to the phase transitioning of phospholipid at higher temperature resulting into less solubility.

On the other hand for entrapment efficiency $\left(\mathrm{Y}_{2}\right)$, drug-phospholipid ratio $\left(\mathrm{X}_{1}\right)$ and reaction temperature $\left(\mathrm{X}_{3}\right)$ had direct relationship while reaction time $\left(\mathrm{X}_{2}\right)$ having an inverse relationship. It was found that highest reaction time of $3.6 \mathrm{~h}$ gave entrapment of $83.44 \%$ while at $1 \mathrm{~h}$ it gave entrapment of $96.86 \%$. This may be due dissociation in hydrogen bonding between CGA phenolic group and choline group of Phospholipon $90 \mathrm{H}$ with longer reaction times. Thus it shows the appropriate time required for CGA to complex with that of phospholipid while the increase in entrapment efficiency with increasing drug-phospholipid ratio and reaction temperature can be attributed to increased phospholipid content at required transition temperature which favors better entrapment of CGA complex [22].

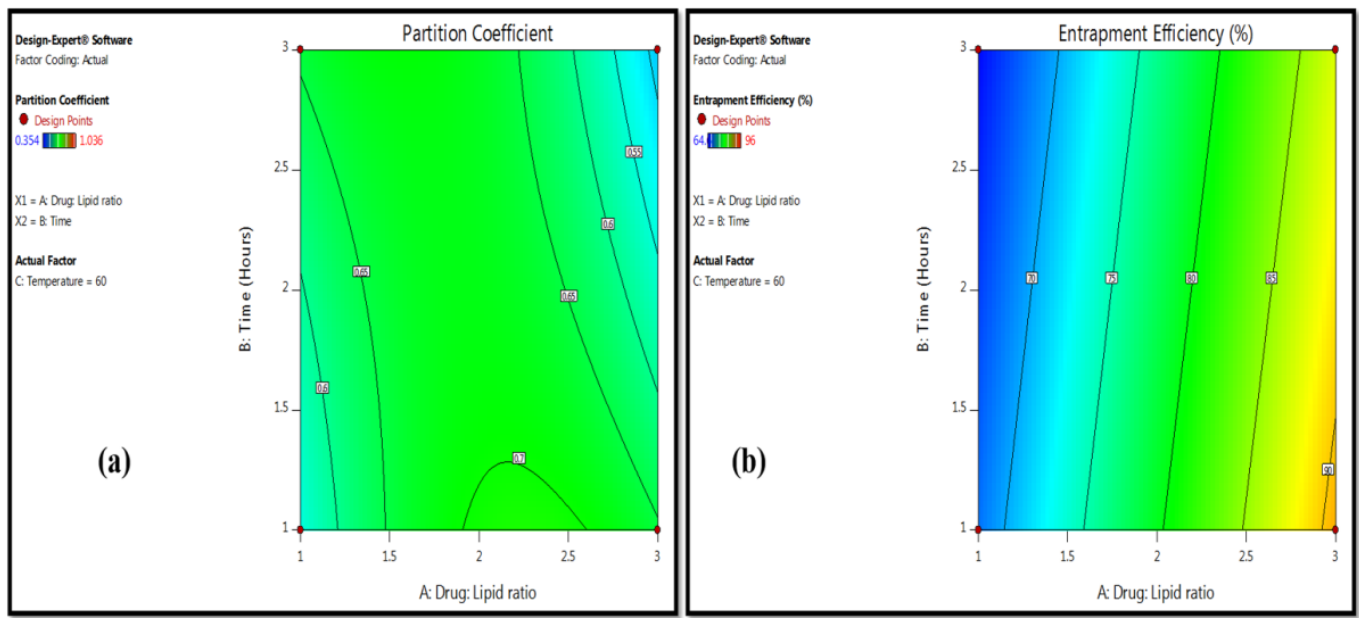

Fig. 1: Contour plots of CGA phytovesicles (a) Partition coefficient (b) Entrapment efficiency

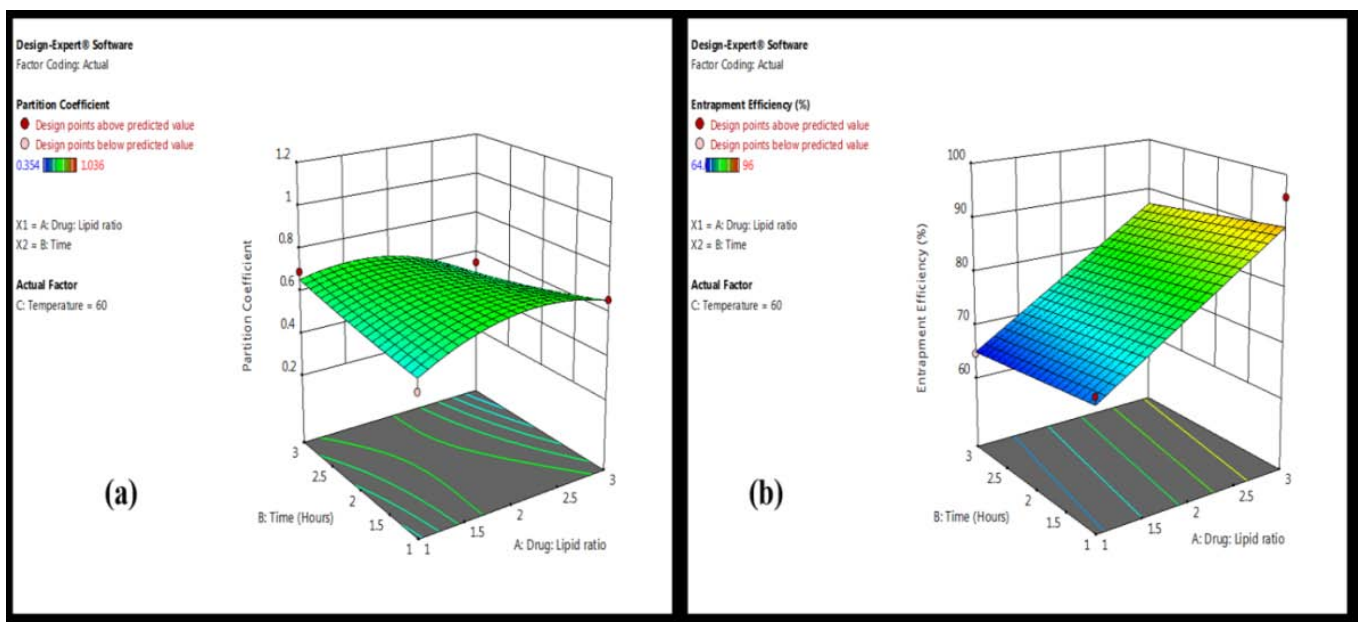

Fig. 2: 3D surface plots of CGA phytovesicles (a) Partition coefficient (b) Entrapment efficiency 
Similar relationship was seen in contour plots and 3D response curves (fig. 1 and 2 respectively). Depending on these observations optimal values of the variables were drawn i.e. $1: 3,1 \mathrm{~h}, 60{ }^{\circ} \mathrm{C}$ respectively. Batch F7 was thus selected as the optimized batch showing highest entrapment with highest partition coefficient where the drug CGA and phospholipid were in the molar ratio of 1:3 thus having better prospects to complex sufficiently with optimum reaction time of $1 \mathrm{~h}$ with $60^{\circ} \mathrm{C}$ of reaction temperature.

The models obtained for both the dependent variables were further validated by preparing an additional batch as per the optimal values of independent variables-1:3, $1 \mathrm{~h}, 60^{\circ} \mathrm{C}$. The predicted values for partition coefficient and entrapment efficiency of CGA phytovesicles from quadratic and 2FI model (respectively) and the actual values from the prepared batch were compared. The partition coefficient and entrapment efficiency of the prepared batch as per optimized conditions were found to be 0.9554 and $93.65 \pm 0.25 \%$ respectively as compared to 0.9265 and $90.85 \pm 0.02 \%$ of the predicted values given by model showing its practicability. Bias was calculated using the Eq. 6.0 was found $(-3.1 \%)$ for partition coefficient and $(-3.08 \%)$ for entrapment efficiency demonstrating the robustness of the generated models [23].

$$
\text { Bias }=\frac{\text { Predicted value-Observed value }}{\text { Predicted Value }} \text { X } 100 \ldots . . . \text { Eq. } 6.0
$$

\section{Validation of analytical method}

Validation of the UV method was performed as per the guidelines approved by ICH. A linear relationship was found between concentrations $(2-22 \mu \mathrm{g} / \mathrm{ml})$ for all the three; methanol, ultrapure water and pH 6.8 PBS with correlation coefficient $\left(\mathrm{r}^{2}\right)$ of 0.9989 , $0.9947,0.9995$ respectively. The $\lambda \max$ was obtained at $328.2 \mathrm{~nm}$ for methanol and $6.8 \mathrm{pH}$ PBS whereas $323.4 \mathrm{~nm}$ for ultrapure water. Accuracy of the analytical method was determined using recovery assay methods where the sample solutions were spiked with analyte at three different concentrations $(18,20,22 \mu \mathrm{g} / \mathrm{ml})$ and percent recovery calculated was $61.3 \%, 59.1 \%, 56.9 \%$ for methanol; $70.8 \%$, $74.3 \%, 76.7 \%$ for ultrapure water; and $44.6 \%, 44.8 \%, 44.2 \%$ for 6.8 $\mathrm{pH}$ PBS. Relative standard deviations of intra and inter day measurements in all the solvents was less than $2 \%$. The limit of quantification and limit of detection values obtained were 0.06 $\mu \mathrm{g} / \mathrm{ml}$ and $0.02 \mu \mathrm{g} / \mathrm{ml}$ for methanol and ultrapure water; $0.10 \mu \mathrm{g} / \mathrm{ml}$ and $0.03 \mu \mathrm{g} / \mathrm{ml}$ for $\mathrm{pH} 6.8$ PBS. The results obtained were in agreement with the literature reported by Navarra et al. [24] and Shikov et al. [25].

\section{Entrapment efficiency and partition coefficient}

Entrapment efficiency of optimized CGA phytovesicles was $96.89 \pm 1.24 \%$ [14] while the partition coefficient of CGA phytovesicle was found to be $0.977 \pm 0.36$ as compared to $0.036 \pm 0.43$ of CGA [26]. This increase in partition coefficient is attributed to the complexation between CGA and phospholipid. The CGA phytovesicle showed better solubility (30 times more) in oil phase $(4.830 \mathrm{mg} / \mathrm{ml}$ ) with solubility in water phase of $4.939 \mathrm{mg} / \mathrm{ml}$ as compared to plain CGA which showed $0.16 \mathrm{mg} / \mathrm{ml}$ of solubility in oil phase and 4.414 $\mathrm{mg} / \mathrm{ml}$ solubility in water phase. Thus the phytovesicle formed was more ampiphilic in nature. Leptihn et al. [27] reported that pka, LogP and hydrophobicity play a major role for a molecule to exert antimicrobial activity. CGA in phytovesicular form showed higher $\log \mathrm{P}$ values with optimum hydrophobicity thus having propensity for improved antimicrobial activity [27].

\section{Characterization of optimized CGA phytovesicles}

\section{FTIR spectroscopy}

Formation of phytovesicle was confirmed by comparing the spectra of the CGA and CGA phytovesicle. The characteristic peaks of CGA were identified as, phenolic and carboxylic $\mathrm{O}-\mathrm{H}$ stretching at $3647.39 \mathrm{~cm}^{-1}, 3672.47 \mathrm{~cm}^{-1}, 3900.07 \mathrm{~cm}^{-1} ; \mathrm{C}=0$ ketonic stretching at $1714.72 \mathrm{~cm}^{-1}$; aromatic $\mathrm{C}=\mathrm{C}$ stretching at $1456.26 \mathrm{~cm}^{-1}$ and 1539.20 $\mathrm{cm}^{-1}$; aromatic ring stretching at $908.47 \mathrm{~cm}^{-1}, 817.82 \mathrm{~cm}^{-1}$ (fig. 3). The spectra of Phospholipon $90 \mathrm{H}$ gave characteristic C-H stretching band of long chain fatty acid at $2916.37 \mathrm{~cm}^{-1}$ and $2848.86 \mathrm{~cm}^{-1}$ [28]. Also, a $\mathrm{C}=0$ band at $1467.83 \mathrm{~cm}^{-1}$; a- a $\left(\mathrm{so}_{3}\right)_{3}$ band at $923.90 \mathrm{~cm}^{-1}$ and a P-O-C stretch at $968.27 \mathrm{~cm}^{-1}[29]$. The spectra of the physical mixture showed all the characteristic bands as those present in CGA and Phospholipon $90 \mathrm{H}$. While in the spectrum of CGA phytovesicle was different from CGA and Phospholipon 90H with absence of $908.47 \mathrm{~cm}^{-1}, 817.82 \mathrm{~cm}^{-1}, 923.90 \mathrm{~cm}^{-1}, 968.27 \mathrm{~cm}^{-1}$ peaks. The peak at $3672.47 \mathrm{~cm}^{-1}$ shifted left to $3687.90 \mathrm{~cm}^{-1}$. Furthermore, the absence of aromatic stretch peaks has been previously attributed to successful formation of phytovesicular complex [30] indicating the hydrogen bonding between phenolic group of CGA with choline group of Phospholipon 90H [14].

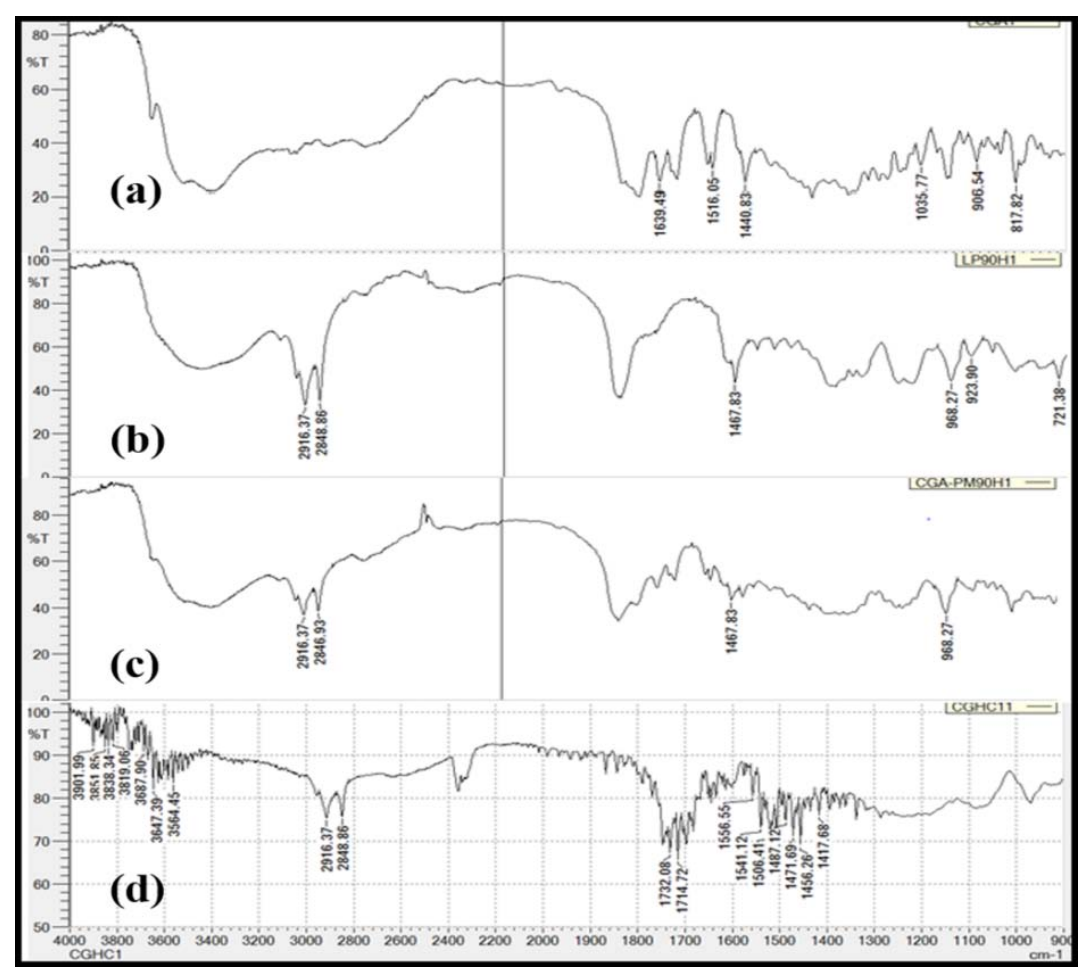

Fig. 3: FTIR spectra of (a) CGA (b) Phospholipon 90H (c) Physical mixture (d) CGA phytovesicle 


\section{Differential scanning calorimetery (DSC)}

Fig. 4 shows the thermograms of CGA, Phospholipon $90 \mathrm{H}$, physical mixture and CGA Phytovesicles. CGA showed two sharp endothermic peaks at with onset at $195.01{ }^{\circ} \mathrm{C}$ and $202.56^{\circ} \mathrm{C}$ which is in consistent with the literature reports [31]. Thermogram of Phospholipon $90 \mathrm{H}$ showed a sharp endothermic peak at onset of $101.43^{\circ} \mathrm{C}$ and additional endothermic peaks at onset of $57.20^{\circ} \mathrm{C}$, and $177.69^{\circ} \mathrm{C}$. The physical mixture of CGA and Phospholipon $90 \mathrm{H}$ retained characteristics peaks of both CGA and Phospholipon 90H, however a new characteristic peak was seen at onset of $70.45^{\circ} \mathrm{C}$ which can be attributed to the probable depression in melting endotherm of Phospholipon $90 \mathrm{H}$, complex or eutectic formation. CGA phytovesicle exhibited an endotherm with an onset at $61.52{ }^{\circ} \mathrm{C}$ and also an endotherm close to characteristic physical mixture peak at $70.45{ }^{\circ} \mathrm{C}$ which clearly indicates the Phytovesicular complex formation. Additionally, disappearance of other characteristic endotherms of CGA and Phospholipon $90 \mathrm{H}$, corroborates the formation of phytovesicular complex.

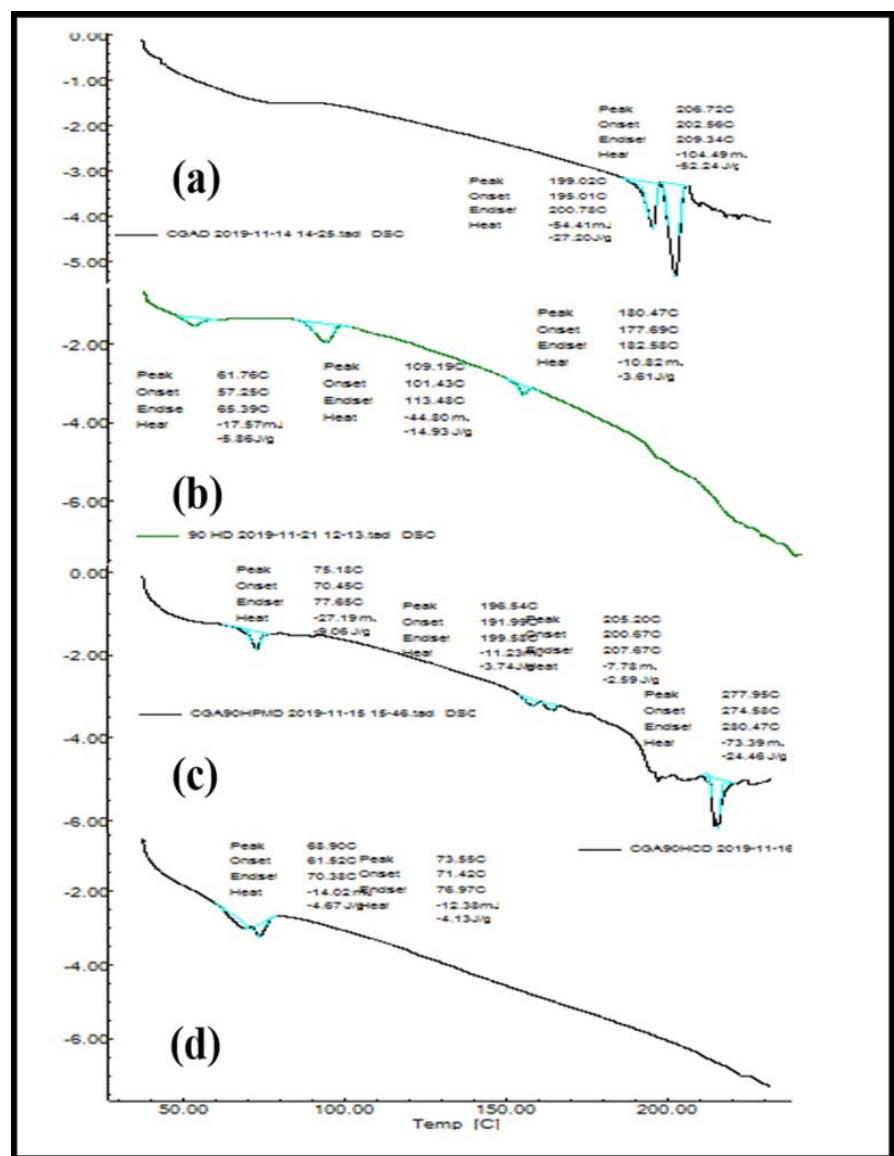

Fig. 4: DSC thermographs of (a) CGA (b) Phospholipon 90H (c) Physical mixture (d) CGA phytovesicle

Particle size analysis

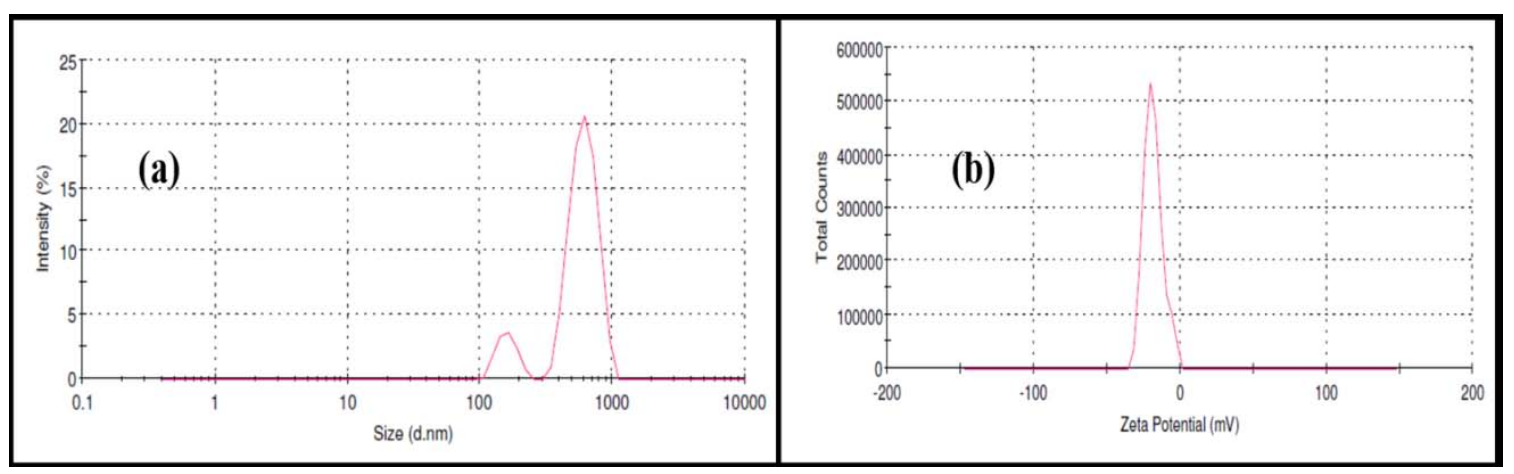

Fig. 5: Particle size (a) and Zeta potential (b) of CGA phytovesicle

Particle size, zeta potential and SEM: The mean particle diameter of optimized phytovesicular complex was found to be $808.6 \pm 1.8 \mathrm{~nm}$ and the polydispersity index obtained as $0.78 \pm 0.06$ indicating a narrow range of particle size distribution [32]. The Zeta potential was found to be (-) 18.6 $66.3 \mathrm{mV}$ (fig. 5) indicating the stability of the formulation. The micrographs of CGA phytovesicles show distinct structures unlike that of the characteristic structures of CGA and Phospholipon 90H (fig. 6). 


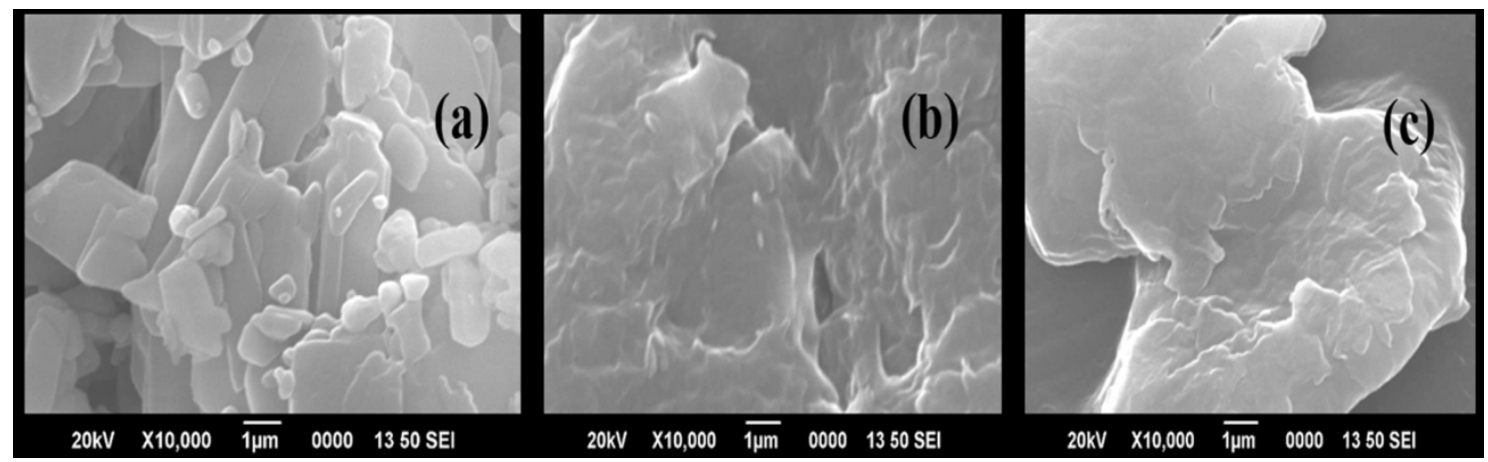

Fig. 6: SEM micrographs of (a) CGA (b) Phospholipon 90H (c) CGA phytovesicle

\section{Anti-microbial activity}

Agar diffusion assay

Table 3: Agar diffusion assay-zone of inhibitions of CGA, CGA phytovesicle along with standard antibiotic Gentamycin against all the four bacterial strains

\begin{tabular}{lllll}
\hline Bacterial strain & \multicolumn{2}{l}{ Zone of inhibition in $(\mathbf{m m})$} & DMSO & GEN \\
\cline { 2 - 5 } & CGA & CGA Phytovesicle & - & $33 \pm 1.15$ \\
& $20 \pm 1.57$ & $25 \pm 1.47$ & - & $29 \pm 3.78$ \\
Staphylococcous aureus & $15 \pm 2.5$ & $22 \pm 3.02$ & - & $30 \pm 1.27$ \\
Klebsiella pneumonia & $17 \pm 1.6$ & $23 \pm 1.52$ & - & $31 \pm 2.0$ \\
Escherichia coli & $16 \pm 2.64$ & $17 \pm 2.08$ & - \\
Bacillus subtilis & &
\end{tabular}

(-) No zone of inhibition, Values were expressed as means \pm SD ( $n=3$ ), CGA, Chlorogenic acid; DMSO, Dimethyl sulfoxide; GEN, Gentamycin

Agar diffusion assay is a standard susceptibility testing for antimicrobials where the antimicrobial agent diffuses into the agar plates and inhibits the growth of the test organism forming growth inhibition zones. Balouiri et al. [33] referred to it as a technique to screen or quantify the antimicrobial effect. CGA in phytovesicular form will give a larger zone of inhibition than plain CGA because of its higher penetrability across cell membrane with higher partition coefficient value[33]. The results obtained from agar diffusion assay are illustrated in table 3. CGA was found to be highly active against all the 4 strains. The zone of inhibition for CGA phytovesicle ranged between $17-25 \mathrm{~mm}$ as compared to CGA showing zone of 15-20 mm at $32 \mathrm{mg} / \mathrm{ml}^{-}$. With increasing concentrations of both the samples, evenly increasing zones of inhibition were found with maximum activity at $32 \mathrm{mg} / \mathrm{ml}^{-}$and a zone of $25 \mathrm{~mm}$ (fig. 7). While the zones obtained with standard antibiotic Gentamycin at equivalent concentration were in the range $30-33 \mathrm{~mm}$ [34].

\section{Minimum inhibitory concentration}

MIC values for CGA and CGA phytovesicles are given in table 4 which showed that CGA inhibited all the 4 strains. The MICs for CGA for all the 4 strains were in the range $500-550 \mu \mathrm{g} / \mathrm{ml}$. While CGA phytovesicles showed the MIC obtained was two times less i.e. 250$300 \mu \mathrm{g} / \mathrm{ml}$ for Staphylococcous aureus, Bacillus subtilis, Klebsiella pneumonia and $200-250 \mu \mathrm{g} / \mathrm{ml}$ for Escherichia coli. The reason for lower MIC values can be the improved physicochemical properties of CGA phytovesicles as compared to that of plain CGA [35]. A relatively higher lipophilic solubility of CGA phytovesicle is responsible for higher microbial membrane permeability ultimately leading to its disruption and cell death. This shows the efficiency of CGA in phytovesicular form with higher antibacterial activity.

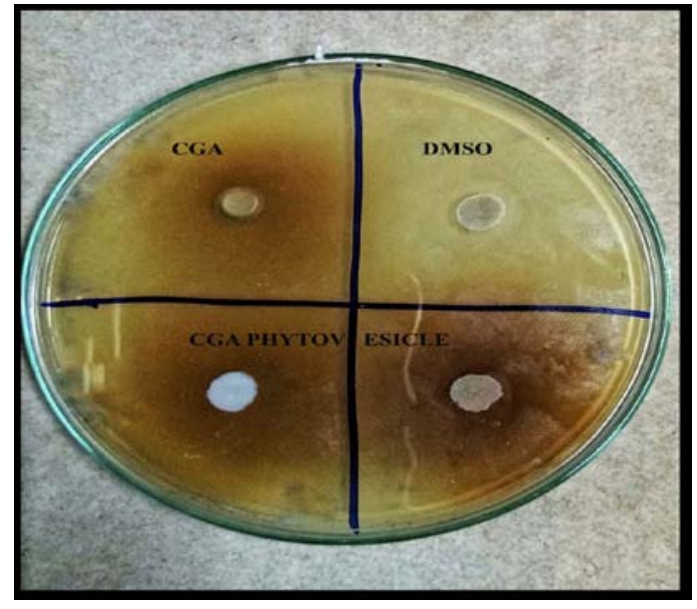

Fig. 7: Agar diffusion assay-Effect of CGA phytovesicle (32 $\mathrm{mg} / \mathrm{ml}^{-1}$ ) on MHA plate inoculated with Staphylococcous aureus (NCIM 2079) by lawn culture technique. CGA phytovesicle showed zone of inhibition larger than CGA while DMSO was used as negative control $(n=3)$

Table 4: Minimum inhibitory concentrations of CGA and CGA phytovesicle against all the four bacterial strains

\begin{tabular}{llc}
\hline Bacterial strain & CGA & CGA phytovesicle \\
\hline Gram positive & $500-550 \mu \mathrm{g} / \mathrm{ml}$ & $250-300 \mu \mathrm{g} / \mathrm{ml}$ \\
Staphylococcous aureus & $500-550 \mu \mathrm{g} / \mathrm{ml}$ & $250-300 \mu \mathrm{g} / \mathrm{ml}$ \\
Bacillus subtilis & & \\
Gram negative & $500-550 \mu \mathrm{g} / \mathrm{ml}$ & $250-300 \mu \mathrm{g} / \mathrm{ml}$ \\
Klebsiella pneumonia & $450-500 \mu \mathrm{g} / \mathrm{ml}$ & $200-250 \mu \mathrm{g} / \mathrm{ml}$ \\
Escherichia coli & & \\
\hline
\end{tabular}

Values are expressed as per the subsequent dilution concentration $(n=3)$ 


\section{Time kill assay}

The effect of time on bactericidal activity of CGA and CGA phytovesicles in all the 4 strains was determined and shown in fig. 8 . There was sharp decrease in the number of viable cells obtained with Escherichia coli and Bacillus subtilis after $6 \mathrm{~h}$ of incubation and a linear decrease in the number of viable cells was found with Staphylococcous aureus and Klebsiella pneumonia after $12 \mathrm{~h}$. This higher resistance with the latter two strains can be explained with the basis of different cell wall composition [36]. A relatively higher lethal effect was observed with CGA phytovesicle after $6 \mathrm{~h}$ of incubation as compared to moderate lethal effect after $12 \mathrm{~h}$ with CGA. This strong bactericidal effect at MIC with a log reduction (1.5 times) in the range of $0.90-2.04$ in CFUs at $24 \mathrm{~h}$ for different strains as compared to 1.38-2.17 of plain CGA can be attributed to the efficiency of phytovesicular form of CGA in crossing the lipid bilayer of the cell and exerting its antimicrobial properties. Moreno et al. [37] reported that the antimicrobial effect of phenolic derivatives is related to inactivation of enzymes in the cell, which are further dependent on rate at which alterations in the cellular membrane and cellular penetration takes place. CGA in phytovesicular form crosses the lipid bilayer of the cell membrane more easily as compared to plain CGA. This loss in integrity of cell membrane causes cell death [37]. Thus a more lethal effect was obtained in phytovesicular form than plain CGA which increased the cell membrane permeability [38].

\section{Effect of pH on antibacterial activity}

Almajano et al. [39] outlined that antimicrobial effect of phenolic derivatives is governed by $\mathrm{pH}$. Thus the effect of $\mathrm{pH}$ on antimicrobial activity on CGA and CGA phytovesicles was assessed and shown in fig. 9. It was found that at $\mathrm{pH} 10$, no bactericidal effect was exerted, while at $\mathrm{pH} 7$ a very weak bactericidal effect was exerted. On the other hand very lethal bactericidal effect was seen at $\mathrm{pH} 4$. The reason for this was described by Narita et al. [40] that phenolic derivatives are more stable under acidic $\mathrm{pH}$ conditions. At higher $\mathrm{pH}$ ( $\geq 7$ ) CGA undergoes irreversible structural changes [41]. It has been reported by Wen et al. [42] that antimicrobial activity of weak acids such as CGA depends on the ionization state and proportion of undissociated molecules of caffeic acid and quinic acid. Hence $\mathrm{pH}$ appeared to be a crucial factor in the bactericidal activity of CGA and parallel effect was seen on the antibacterial activity of CGA phytovesicles with less CFUs at lower $\mathrm{pH}$ as compared to plain CGA.

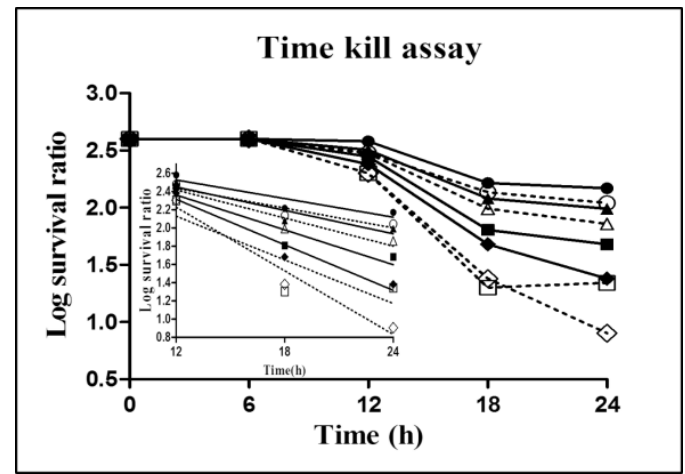

Fig. 8: Time kill assay-Effect of (-)CGA and (---)CGA phytovesicles on viability of (-•-/--O--)Staphylococcous aureus(NCIM 2079), (---/----)Bacillus subtilis (NCIM

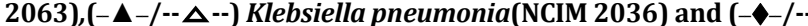
$\checkmark--)$ Escherichia coli(NCIM 2345) at MIC concentrations ( $(n=3)$

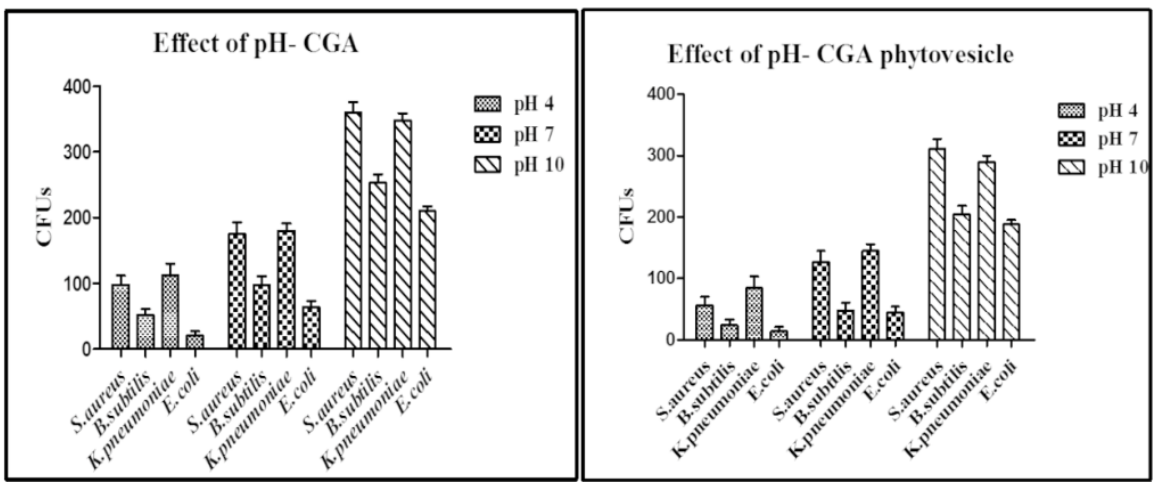

Fig. 9: Effect of pH on the antimicrobial activity of CGA and CGA phytovesicle against Staphylococcous aureus (NCIM 2079), Bacillus subtilis (NCIM 2063), Klebsiella pneumonia (NCIM 2036) and Escherichia coli (NCIM 2345) at MIC concentrations at $37^{\circ} \mathrm{C}$ for $3 \mathrm{~h}$. Three different pH (pH4, pH7 and pH 10) were assessed. CGA phytovesicles gave lower CFUs as compared to plain CGA (n=3)

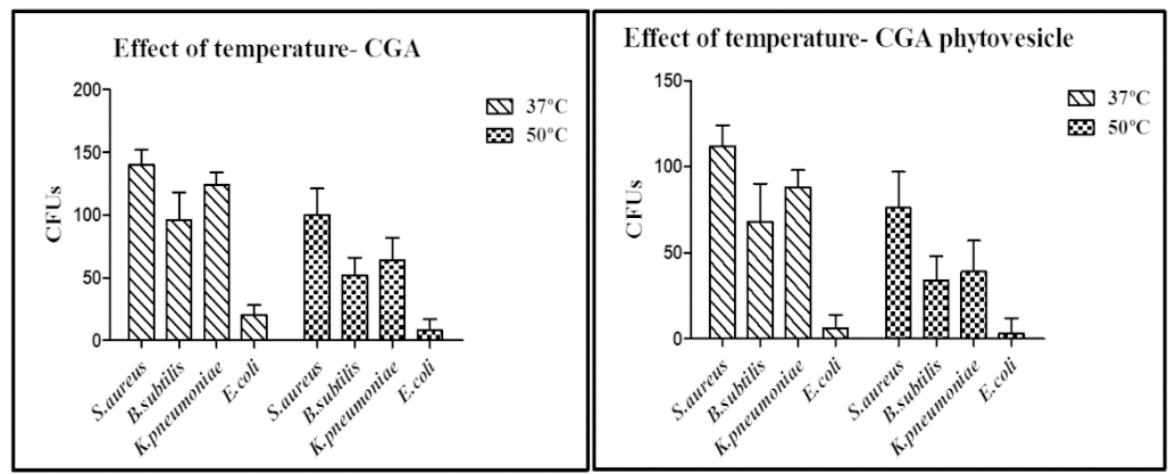

Fig. 10: Effect of thermal stress on the antimicrobial activity of CGA and CGA phytovesicle against Staphylococcous aureus(NCIM 2079), Bacillus subtilis (NCIM 2063), Klebsiella pneumonia(NCIM 2036) and Escherichia coli(NCIM 2345) at MIC concentrations on two different temperatures $37^{\circ} \mathrm{C}$ and $50{ }^{\circ} \mathrm{C}$ for a period of $3 \mathrm{~h}$. Decrease in CFUs was found with CGA phytovesicle $(\mathrm{n}=3)$ 


\section{Effect of temperature on antibacterial activity}

An effect of temperature on the bactericidal effect of CGA and CGA phytovesicles was studied which showed that a moderate bactericidal effect was observed at $37{ }^{\circ} \mathrm{C}$ and a marked bactericidal effect was obtained at $50{ }^{\circ} \mathrm{C}$ for all the 4 strains especially on Escherichia coli (fig. 10). While CGA phytovesicles showed further reduction in the CFUs with increased temperature. This was explained by Kabir et al. [20] and Lou et al. [43] who reported that the role of temperature in antimicrobial action was due to increased permeability of CGA through the bacterial cell walls. They also highlighted that the mechanism for temperature mediated membrane permeability may be because of cell wall disruption at specific temperature leading to cell death [20]. Hence the role of temperature in bactericidal effect of CGA and CGA phytovesicles was determined.

\section{CONCLUSION}

In present study, phytovesicular delivery of CGA provided a greater antibacterial activity over plain CGA. Increased antibacterial activity of CGA in phyovesicular form can be attributed to its improved lipophilic solubility (partition coefficient), which in turn should facilitate an increase in its permeability across bacterial cell wall bilayer. Thereby, reducing the MIC and kill time nearly to half of its plain drug form. The antibacterial activity was largely dependent on both $\mathrm{pH}$ and temperature. Phytovesicles exerted a marked antimicrobial action on both Gram negative [Klebsiella pneumonia and Escherichia coli] and Gram positive [Staphylococcous aureus and Bacillus subtilis] microbes. In order of sensitivity to CGA phytovesicles, the microorganisms are Escherichia coli>Bacillus subtilis $>$ Staphylococcous aureus $>$ Klebsiella pneumonia. All these strains are associated with various types of infections including Urinary tract infections, wound infections, meningitis, nosocomial infections etc. Demonstration of enhanced antimicrobial activity against these test bacteria indicate that there is a possibility of CGA phytovesicle as an alternative source of potential antibacterial agent.

\section{ACKNOWLEDGEMENT}

Authors are grateful to Head, Department of Pharmaceutical Sciences, R. T. M. Nagpur University for providing facilities. The authors acknowledge LIPOID GmbH Germany for providing the gift sample of Phospholipon $90 \mathrm{H}$ for the research study. The facilities provided by the R. C Patel Institute of pharmaceutical Education and Research, Shirpur for DSC studies and Sophisticated Analytical Instruments Facility, STIC. Cochin, India for SEM studies are gratefully acknowledged.

\section{FUNDING}

Nil

\section{AUTHORS CONTRIBUTIONS}

Hemangi Trivedi: Conceptualization, Methodology, Software, Validation, Formal analysis, Investigation, Data Curation, WritingOriginal Draft, Writing-Review and Editing, Project administration.

Prashant K. Puranik: Conceptualization, Methodology, Validation, Resources, Writing-Review and Editing, Visualization, Supervision.

\section{CONFLICT OF INTERESTS}

The authors report no conflicts of interest. The authors alone are responsible for the content and writing of this article.

\section{REFERENCES}

1. Liu RH. Health benefits of fruit and vegetables are from additive and synergistic combinations of phytochemicals. Am J Clin Nutr. 2003;78 Suppl:3-6.

2. Rahman M, Sarker SD. Antimicrobial natural products. Annu Rep Med Chem. 2020;55:77-113.

3. Gupta M. Inorganic nanoparicles: an alternative therapy to combact drug resistant infections. IJPPS. 2021;13(8):20-31.

4. Karunanidhi A, Thomas R, Van Belkum A, Neela V. In vitro antibacterial and antibiofilm activities of chlorogenic acid against clinical isolates of stenotrophomonas maltophilia including the trimethoprim/sulfamethoxazole resistant strain. Biomed Res Int. 2013;10:1-7.

5. Naveed M, Hejazi V, Abbas M, Kamboh AA, Khan GJ, Shumzaid M, et al. Chlorogenic acid (CGA): A pharmacological review and call for further research. Biomed Pharmacother. 2018;97:67-74.

6. Lou Z, Wang H, Zhu S, Ma C, Wang Z. Antibacterial activity and mechanism of action of chlorogenic acid. J Food Sci. 2011;76(6):398-403.

7. Canillac N, Mourey A. Effects of several environmental factors on the anti-Listeria monocytogenes activity of an essential oil of Picea excelsa. Int J Food Microbiol. 2004;92(1):95-103.

8. Li BH, Ma XF, Wu XD, Tian WX. Inhibitory activity of chlorogenic acid on enzymes involved in the fatty acid synthesis in animals and bacteria. IUBMB Life. 2006;58(1):39-46.

9. Zhang F, Zhai T, Haider S, Liu Y, Huang ZJ. Synergistic effect of chlorogenic acid and caffeic acid with fosfomycin on growth inhibition of a resistant Listeria monocytogenes strain. ACS Omega. 2020;5:7537-44.

10. Gil M, Wianowska D. Chlorogenic acids-their properties, occurrence and analysis. Ann Univ Mariae Curie-Sklodowska, Sect AA-Chem. 2017;72(1):61.

11. Olthof MR, Hollman PCH, Katan MB. Chlorogenic acid and caffeic acid are absorbed in humans. J Nutr. 2001;131(1):6671.

12. Shi G. Yeast-cell-based microencapsulation of chlorogenic acid as a water-soluble antioxidant. J Food Eng. 2007;80:1060-7.

13. Tripathy S, Patel DK, Barob L, Naira SK. Review on phytosomes, their characterization, advancement and potential for transdermal application. J Drug Deliv Ther. 2013;3(3):147-52.

14. Bhattacharyya S, Majhi S, Saha BP, Mukherjee PK. Chlorogenic acid-phospholipid complex improve protection against UVA induced oxidative stress. J Photochem Photobiol B Biol. 2014;130:293-8.

15. Yue P, Yuan H, Li X, Yang M, Zhu W. Process optimization, characterization and evaluation in vivo of oxymatrinephospholipid complex. Int J Pharm. 2010;387(1-2):139-46.

16. European Medicines Agency. ICH Topic Q 2 a validation of analytical methods: definitions and terminology. ICH Tech Coord. 1994. p. 1-5.

17. Murthy SBR, Yelavarthi P, Devanna N. Process of orlistat loaded chitosan nanoparticles using box behnken design-an evaluation study. Asian J Pharm Clin Res. 2021;14(5):103-11.

18. Rahmi IA, Munim A, Jufri M. Formulation and evaluation of phytosome lotion from Nothopanax scutellarium leaf extract for hair growth. IJAP. 2021;13(6):178-85.

19. Ganna S, Kotakadi SM, Mohammed RA, Shaik MI, Nannepaga JS. Optimization and characterization of rivastigmine loaded nanostructured lipid carriers. IJCPR. 2021;13(3):46-51.

20. Kabir F, Katayama S, Tanji N, Nakamura S. Antimicrobial effects of chlorogenic acid and related compounds. J Korean Soc Appl Biol Chem. 2014;57(3):359-65.

21. Das MK, Kalita B. Design and evaluation of phyto-phospholipid complexes (phytosomes) of Rutin for transdermal application. J Appl Pharm Sci. 2014;4(10):51-7.

22. Ahmad R, Uma P. Preparation and characterization of embelinphospholipid complex as effective drug delivery tool. J Incl Phenom Macrocycl Chem. 2011;69:139-47.

23. Telange DR, Patil AT, Pethe AM, Fegade H, Anand S, Dave VS. Formulation and characterization of an apigenin-phospholipid phytosome (APLC) for improved solubility, in vivo bioavailability, and antioxidant potential. Eur J Pharm Sci. 2017;108:36-49.

24. Navarra G, Moschetti M, Guarrasi V, Mangione MR, Militello V, Leone M. Simultaneous determination of caffeine and chlorogenic acids in green coffee by UV/Vis spectroscopy. J Chem. 2017;5:1-8.

25. Shikov AN, Kosman VM, Makarov VG, Hptlc, VM Kosman, VG Makarov TLC. Original paper comparison of high performance TLC and HPLC for separation and quantification of chlorogenic acid in green coffee bean extracts. J Sep Sci 2008;31:237-41.

26. Semalty A, Semalty M, Singh D, Rawat MSM. Preparation and characterization of phospholipid complexes of naringenin for effective drug delivery. J Incl Phenom Macrocycl Chem. 2010;67(3):253-60. 
27. Leptihn S, Har JY, Wohland T, Ding JL. Correlation of charge, hydrophobicity, and structure with antimicrobial activity of S1 and MIRIAM peptides. Biochemistry. 2010;49(43):9161-70.

28. Ittadwar PA, Puranik PK. Novel umbelliferone phytosomes: development and optimization using experimental design approach and evaluation of photo protective and antioxidant activity. IJPPS. 2017;9(1):218-20.

29. Saoji SD, Raut NA, Dhore PW, Borkar CD, Popielarczyk M, Dave VS. Preparation and evaluation of phospholipid-based complex of standardized Centella extract (SCE) for the enhanced delivery of phytoconstituents. AAPS J. 2016;18(1):102-14.

30. Liang N, Lu X, Hu Y, Kitts DD. Application of attenuated total reflectance-fourier transformed infrared (ATR-FTIR) spectroscopy to determine the chlorogenic acid isomer profile and antioxidant capacity of coffee beans. J Agric Food Chem. 2016;64(3):681-9.

31. Chao J, Wang $\mathrm{H}$, Zhao $\mathrm{W}$, Zhang $\mathrm{M}$, Zhang L. Investigation of the inclusion behavior of chlorogenic acid with hydroxypropyl- $\beta$ cyclodextrin. Int J Biol Macromol. 2012;50(1):277-82.

32. Ittadwar PA, Bhojne SV, Puranik PK. Novel salicin phytosomal complex: development and optimization using central composite design. WJPR. 2018;7(9):735-51.

33. Balouiri M, Sadiki M, Ibnsouda SK. Methods for in vitro evaluating antimicrobial activity: a review. J Pharm Anal. 2016;6(2):71-9.

34. Padalia H, Chanda S. Antimicrobial efficacy of different solvent extracts of Tagetes erecta $L$. flower, alone and in combination with antibiotics. Appl Microbiol. 2015;1(1):1-10.
35. Fattouch S, Caboni P, Coroneo V, Tuberoso CIG, Angioni A, Dessi $\mathrm{S}$, et al. Antimicrobial activity of tunisian quince (Cydonia oblonga Miller) pulp and peel polyphenols extracts. J Agric Food Chem. 2007;55(3):963-9.

36. Taguri T, Tanaka T, Kouno I. Antimicrobial activity of 10 different plant polyphenols against bacteria causing food-borne disease. Biol Pharm Bull. 2004;27(12):1965-9.

37. Moreno S, Scheyer T, Romano CS, Vojnov AA. Antioxidant and antimicrobial activities of rosemary extracts linked to their polyphenol composition. Free Radical Res. 2006;40(2):223-31.

38. Appiah T, Boakye YD, Agyare C. Antimicrobial activities and time-kill kinetics of extracts of selected ghanaian mushrooms. eCAM. 2017;10:1-15.

39. Almajano MP, Carbo R, Delgado ME, Gordon MH. Effect of pH on the antimicrobial activity and oxidative stability of oil-in-water emulsions containing caffeic acid. J Food Sci. 2007;72(5):C25863. https://doi.org/10.1111/j.1750-3841.2007.00387.x

40. Narita Y, Inouye K. Degradation kinetics of chlorogenic acid at various $\mathrm{pH}$ values and effects of ascorbic acid and epigallocatechin gallate on its stability under alkaline conditions. J Agric Food Chem. 2013;61(4):966-72.

41. Friedman M, Jurgens HS. Effect of $\mathrm{pH}$ on the stability of plant phenolic compounds. J Agric Food Chem. 2000;48(6):2101-10.

42. Wen A, Delaquis P, Stanich K, Toivonen P. Antilisterial activity of selected phenolic acids. Food Microbiol. 2003;20(3):305-11.

43. Lou Z, Wang H, Lv W, Ma C, Wang Z, Chen S. Assessment of antibacterial activity of fractions from burdock leaf against food-related bacteria. Food Control. 2010;21(9):1272-8. 